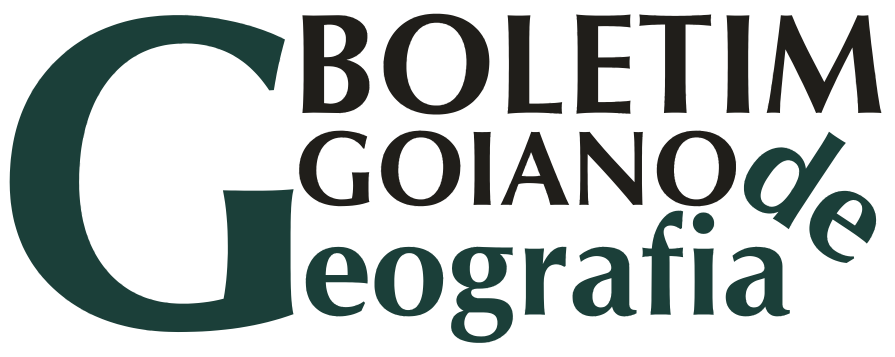

INSTITUTO DE ESTUDOS

SÓCIO-AMBIENTAIS/GEOGRAFIA

VOL. 23 - No 1 - JAN./ JUN. 2003

$\infty$
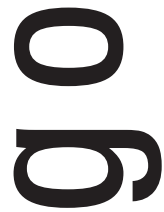

$\square$
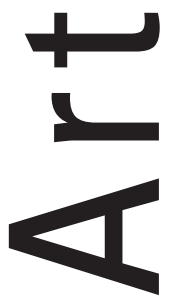


\section{REENCONTRANDO A CIDADE: \\ UM ENSAIO SOBRE A CONFIGURAÇÃO DAS METRÓPOLES NA CONTEMPORANEIDADE - SEUS DILEMAS E PERSPECTIVAS}

Rosemere Maia*

\section{Resumo}

A cidade, em especial a metrópole, será aqui analisada, com seus atores, sua (des)organização interna, seus conflitos e seus fragmentos, apesar de estarmos conscientes de que a complexidade do mundo urbano não nos permitirá apreendê-lo em toda sua riqueza e magnitude, nem tampouco dar conta da totalidade de suas (con)tradições, simbolismos, ideologias e práticas socioespaciais. Propomo-nos, assim, a fazer uma breve discussão sobre a forma como as cidades, de modo especial, as "cidades grandes", vêm influenciando nas mudanças que se processam na sociedade (em seus variados aspectos: econômicos, políticos, culturais, ideológicos), neste início de milênio. Tentaremos, para tanto, expor algumas questões que nos instiguem a desvendar tais mudanças e, ao mesmo tempo, coloquem-nos o desafio de tentar antever alguns elementos indicadores do "destino das cidades".

Unitermos: Cidade/ Sociabilidade/ Segregação/ Consumo.

Parece-nos cada vez mais distante o tempo em que as cidades e as relações sociais que lhes davam sentido e inteligibilidade articulavam-se, basicamente, em torno da produção, e a esse processo estavam estritamente vinculadas as "formas" que o mundo urbano assumia.

É sabido que a concentração das grandes indústrias no interior das cidades modernas, no momento de seu incremento, era uma de suas referências fundamentais - quiçá sua razão de ser! Urbanização e industrialização pareciam, assim, duas faces de uma mesma moeda. Hoje, a situação colocase sob matizes bastante diferenciados. As mudanças ocorridas no mundo do trabalho, a partir do que se convencionou chamar de Terceira Revolução Industrial, contribuíram, outrossim, para as alterações significativas que se vêm processando, nas últimas décadas, na organização e estruturação interna

*Professora da Escola de Serviço Social da Universidade Federal do Rio de Janeiro; Doutora em Geografia e pesquisadora da FAPERJ 
MAIA, Rosemere. Reencontrando a cidade - um ensa1o sobre a configuração das metrópoles na comtemporaneidade... Boletim Goiano de Geografia, 23 (1): 23 -40, jan./jun. 2003

das cidades.

A industrialização pautada na microeletrônica - logo, caracterizada pela alta tecnologia - acabou, como sugeriu Soja (1994, p. 159), por afetar a lógica do espaço urbano. Da concentração de indústrias em grandes parques, passamos a uma era onde a tônica tem sido, conforme salienta Castells (1999, p. 412),

a separação do processo produtivo em diferentes localizações, ao mesmo tempo em que reintegra sua unidade por meio de conexões de telecomunicações e da flexibilidade e precisão resultante da microeletrônica na fabricação de componentes. Além disso, devido à singularidade da força de trabalho necessária para cada estágio e às diferentes características sociais e ambientais próprias das condições de vida de segmentos profundamente distintos desta força de trabalho, recomenda-se especificidade geográfica para cada fase do processo produtivo. Isto implica, obviamente, não somente nesta especificidade geográfica, mas outrossim numa localização espacial igualmente distinta entre os diferentes grupos formadores da mão-de-obra necessária: força de trabalho altamente qualificada, trabalhadores médios e massa de trabalhadores não qualificados dedicados à montagem de rotina e às operações auxiliares (estes sendo, paulatinamente, "substituídos" por máquinas).

No modelo de industrialização anterior, a contigüidade espacial era, para além de uma mera característica, necessária e coerente à sua própria lógica. O modelo atual, ao contrário, caracteriza-se pela descontinuidade geográfica, cabendo aos complexos industriais organizarem-se em redes, com os mais variados fluxos de informações, o que deixa claro um paradoxo essencial: ao mesmo tempo em que se reúnem, essas redes com seus fluxos separam os componentes territoriais (Castells, 1999, p. 419). A dinâmica urbana, mais e mais, parece escapar de definições pautadas em "velhos" dualismos, como centro-periferia, urbano-suburbano, rural-urbano etc.

As mudanças ocorridas no mundo do trabalho e as crescentes transformações por que passa o processo de industrialização acabam impactando, como nos demonstra Soja (1994, p. 162), "na estrutura socioeconômica da metrópole, nas relações de classes e na estratificação de renda, na organização do trabalho e no mercado imobiliário, bem como na própria natureza da produção social e do consumo de bens e serviços". Poderíamos ainda ir além: tais mudanças têm 
MAIA, Rosemere. Reencontrando a cidade - um ensaio sobre a configuração das metrópoles na comtemporaneidade... Boletim Goiano de Geografia, 23 (1): 23 -40, jan./jun. 2003

implicado transformações significativas nos aspectos culturais e simbólicos e na própria subjetividade.

Já não se pode pensar, por exemplo, que a construção da identidade dos citadinos parte tão-somente da esfera da produção e fica polarizada entre burgueses e proletários. Soja (1994, p. 164) sustenta que a cidade contemporânea (ou, sob sua ótica, "a cidade pós-moderna") "possui uma estrutura social desestabilizada e desorganizada cuja dualidade consiste, cada vez mais, numa 'subclasse' amorfa e heterogênea e numa 'superclasse' amorfa de executivos, empresários, corretores e artistas".

A concentração populacional nas cidades, em todas as partes do planeta, assume, na contemporaneidade, índices incríveis e, ao mesmo tempo, assustadores. De apenas um quarto da população mundial moradora nas cidades em meados do século XX, passamos, hoje, a um terço residente só em metrópoles com mais de um milhão de habitantes. No Brasil, temos duas "megacidades", São Paulo e Rio de Janeiro, que contam juntas com mais de quinze milhões de habitantes. Para 2025, estima-se que mais de cinco bilhões de pessoas estarão vivendo em metrópoles em todo o mundo.

As cidades não só tiveram um aumento significativo no número de habitantes, como também vêm passando por um processo de complexificação. Surge uma multiplicidade de atores, de identidades, de lógicas, de relações e conflitos, de "pedaços" e, por isso mesmo, de possibilidades de análise. Essa multiplicidade demonstra que muito do que se falou sobre as cidades já se tornou anacrônico e, seguindo a mesma lógica, o que sobre elas se fala, hoje, talvez não dê conta de sua compreensão num futuro bem próximo.

A visão que cada um de nós acredita deter a seu respeito é capaz de alcançá-las apenas parcialmente, não só em função de sua magnitude, mas, outrossim, de seu dinamismo e mutabilidade, que, em frações de segundo, alteram todo um contexto que tomávamos como familiar. Deste modo, nosso discurso em relação à cidade torna-se fluido, rapidamente desatualizado, insustentável, situação esta que, segundo Castro (1998, p. 145), tem a ver com a "velocidade da transformação do espaço, [que muitas vezes faz que] o sujeito se sinta estranho onde morou por décadas: estrangeiro no seu próprio hábitat".

Mumford (1991) faz-nos refletir sobre uma grande contradição que as 
MAIA, Rosemere. Reencontrando a cidade - um ensa1o sobre a configuração das metrópoles na comtemporaneidade... Boletim Goiano de Geografia, 23 (1): 23 -40, jan./jun. 2003

metrópoles carregam. Aquilo que, aos olhos do povo do interior, parece hostil e alheio, é, a bem da verdade, a essência da grande cidade. Segundo o autor,

dentro de um perímetro relativamente estreito, ela ajuntou a diversidade e a variedade das culturas especiais; pelo menos em quantidades apreciáveis, todas as raças e culturas podem ali ser encontradas, juntamente com suas línguas, seus modos, seus costumes, suas cozinhas típicas; ali, os representantes da humanidade se encontraram pela primeira vez frente a frente, em terreno neutro. A complexidade e a abrangência cultural da metrópole abarcam a complexidade e a variedade do mundo como um todo. Inconscientemente, as grandes capitais vêm preparando a espécie humana para as associações e unificações maiores que a moderna conquista do tempo e do espaço tornaram prováveis, senão inevitáveis. (p. 605)

Vale lembrar que, no momento em que Mumford escreveu sua obra (início da década de 1960), as questões que ora são palpáveis eram experimentadas pelo autor como tendência, ou, talvez, apenas como presságio.

A cidade contemporânea, agigantada em sua fisiologia e simbologia, costuma dar-se aos olhos dos citadinos como grande desconhecida e, em alguma medida, como "inspiradora de medo". A promessa trazida pela modernidade em relação a ela, tendo como preceito fundante sua racionalização econômicoadministrativa e considerando-a fator de progresso social e de consolidação da democracia, parece, para alguns, evanescente. Mais e mais, torna-se patente a dificuldade de transformar a cidade em objeto de intervenção planejada e racional e de se exercer sobre ela (e seus diferentes atores) um pleno controle.

Palco de estranhamento, de isolamento, de violência e solidão, a cidade contemporânea afirma, assim, a contradição entre a cultura e a barbárie, a exemplo do que nos foi sugerido por Benjamin, apud Castro (1998, p. 143).

A perda do sentido do lugar (Lynch, 1991, p. 92), da identidade na e com a cidade (de modo especial nas metrópoles) e a transformação acelerada de muitas das referências espaciais são elementos que parecem caracterizar a contemporaneidade. A vivência cotidiana restringe-se aos limites dos apartamentos, no máximo às muralhas e grades que circundam os condomínios, e, em alguma medida, estende-se aos escritórios, aos shopping centers, aos supermercados. A rua, paulatinamente, perde seu sentido clássico de "lugar de 
MAIA, Rosemere. Reencontrando a cidade - um ensaio sobre a configuração das metrópoles na comtemporaneidade... Boletim Goiano de Geografia, 23 (1): 23 -40, jan./jun. 2003

socialização construído no tempo, definido pela pluralidade de suas funções de residência, de troca, de consumo, de relações humanas informais, de vida coletiva" (Chesneaux, 1996, p. 21). Ao contrário, torna-se mero canal de circulação, de passagem.

Tornada estranha, "guetificada", não experimentada em sua plenitude, a cidade deixa, assim, de promover relações sociais e políticas mais amplas. A cisão existente nessa esfera manifesta-se espacialmente, demonstrando partições na geografia do mundo urbano. E esse é um fato perfeitamente explicável, posto ser o espaço não somente uma dimensão física e material, mas um construto e construtor de relações sociais.

A vida política nas cidades, tão efervescente em outros momentos de sua história, apresenta-se hoje extremamente comprometida, sendo um dos elementos a contribuir para tal estado de coisas justamente essa tendência de busca da intimidade. De maneira bastante elucidativa, Sennett (1998) expõenos elementos que tornam transparente esse iminente "declínio do homem público" na contemporaneidade. A suspeita e a intolerância diante da diferença, juntamente com a necessidade de isolar e banir os estranhos, têm levado à criação de "comunidades" uniformes e segregadas dos pontos de vista étnico e de classe.

Esses espaços auto-segregados são duplamente desfavoráveis ao amadurecimento da vida política coletiva, não possibilitando o encontro, a ação conjunta. Neles vigora o narcisismo, o hedonismo, a preocupação com o ego. Entre aqueles que os buscam, alguns, talvez mais conscientes, parecem ressentidos com a exclusão que sofrem diante das arenas políticas, o que determina uma falta de poder (Giddens, 1991, p. 125), mas praticamente não vêem alternativa para equacionar essa questão: em grande medida, constatam que, na cidade contemporânea, "as pessoas se entrecruzam e não se conhecem, refugiando-se no espaço-refúgio da habitação privada. Que sociedade nova pode surgir daí, que novas formas de vida política, que novos lugares de memória?" (Chesneaux, 1996, p. 37).

Não raras vezes, têm -se justificado pelo medo os processos de autosegregação, em franca disseminação nas grandes cidades. Esse sentimento, como podemos constatar, é diametralmente oposto àquele experimentado pelos moradores das cidades de outrora. Antes, tinha-se medo daqueles vindos 
de fora, potencialmente vistos como inimigos. Por isso cercava-se a cidade e construíam-se muralhas, na tentativa de evitar invasões, pilhagens ou guerras, a exemplo do que é discutido por Aristóteles na sua Política, ao tratar da importância das muralhas na proteção da pólis.

Ter a pretensão de não circundar a cidade de muralhas é criar um país fácil de ser invadido [...] nem se deve esquecer que uma cidade cercada de muralhas pode ou não servir-se delas, ao passo que, se absolutamente não as possui, a escolha é impossível. Se assim é, pois, deve-se não só construir muralhas à volta da cidade, mas ainda delas cuidar, a fim de que sirvam ao ornamento e à suntuosidade do lugar. (Aristóteles, s.d., p. 88)

Nos dias de hoje, os muros construídos cruzam a própria cidade, em várias direções, nos shopping centers e condomínios, que criam toda sorte de mecanismos para protegerem-se de um inimigo que, historicamente, vem tendo sua imagem associada à violência, ao banditismo: os segmentos pobres ou, como se tem preferido dizer, os excluídos. Podemos perceber, com isso, que tanto os shopping, quanto os condomínios, ao utilizarem as mais variadas estratégias de vigilância/proteção, não o fazem tão-somente por razões operacionais, mas sobremaneira por razões políticas e ideológicas.

Em relação às tendências ao aprisionamento, ao controle social e à vigilância, constatados no mundo urbano, Soja (1994, p. 165) reporta-se à Foucault e toma emprestada a expressão "cidade carcerária", para designar o lugar onde a "polícia substitui a polis". Tanto se apresentando explicitamente - por intermédio de diferentes instituições que visam manter sobre os citadinos o imperativo da ordem -, como se configurando através de outros mecanismos de segurança e vigilância, acionados por diferentes sujeitos a fim de evitar a importunação por parte de segmentos indesejáveis, "a obsessão com a segurança permeia a psicogeografia da metrópole pós-moderna, encorajando as autoridades a manterem sob controle todos os fragmentos e polaridades, todas as orlas e adjacências" (Soja, 1994, p. 165).

A privatização da vida, iniciada no século passado e aprofundada neste, pode nos servir ao entendimento de um sem-número de práticas presentes na contemporaneidade e que refletem na criação de estratégias objetivas de confinamento, de recusa de contato com o que se considera hostil, com o inimigo. Isso 
MAIA, Rosemere. Reencontrando a cidade - um ensaio sobre a configuração das metrópoles na comtemporaneidade... Boletim Goiano de Geografia, 23 (1): 23 -40, jan./jun. 2003

porque a cidade transformou-se num território sem leis, mesmo congregando a possibilidade do encontro, da troca.

A celebração do gueto, objetivada na busca dos espaços privativos e auto-segregados, está em perfeita sintonia com a lógica do capitalismo, cuja premissa fundamental é, justamente, o princípio da dissociação, da alienação. O modo de produção capitalista não só supõe tal princípio nas relações de produção, quanto o reforça, cotidianamente, nas mais diferentes instâncias da vida dos indivíduos. Conforme sugere Sennett (1998, p. 359-360),

aquilo que precisamente se perde com essa celebração (do gueto) é a idéia de que as pessoas só podem crescer através de processos de encontro com o desconhecido. Coisas e pessoas que são estranhas podem perturbar idéias familiares e verdades estabelecidas; o terreno não familiar tem uma função positiva na vida de um ser humano. Essa função é a de acostumar o ser humano a correr riscos. O amor pelo gueto, especialmente o gueto de classe média, tira da pessoa a chance de enriquecer as suas percepções, a sua experiência, e de aprender a mais valiosa de todas as lições humanas: a habilidade para colocar em questão as condições já estabelecidas de sua vida.

$\mathrm{O}$ ato de circular (ou se trancafiar) em espaços privativos, desejando, com isso, a defesa contra o mundo exterior, marcado pela violência, pela hostilidade, não chega a interferir, positivamente, na mudança do quadro de caos ou de guerra civil instaurada em alguns locais. Ao contrário de ser uma forma de combate aos males da sociedade capitalista, tal medida "resulta numa espécie bizarra de retraimento despolitizado; o sistema permanece intacto; mas talvez consigamos fazer com que nosso torrão não seja afetado" (Sennett, 1998, p. 360). Esse clima de guerra civil, marcado pela criminalidade violenta, tem levado cada um de nós a sustentar uma teoria a seu respeito, a exemplo do que nos demonstra Soares (1996, p. 284):

Estas teorias comportam pelo menos quatro tipos de asserção, cujas referências são: o que está acontecendo na cidade; por que razão este processo está em curso; o que deveria ser feito para interrompê-lo; qual a natureza dessas convicções. Em outras palavras, desde as autoridades até as vítimas, dos políticos aos policiais, passando pelos pesquisadores acadêmicos, praticamente todos os atores do drama, direta ou indiretamente envolvidos nas ocorrências policiais, sustentam 

comtemporaneidade... Boletim Goiano de Geografia, 23 (1): 23 -40, jan./jun. 2003

um diagnóstico, uma terapia, uma hipótese genealógica e uma concepção epistemológico-metodológica sobre o grande objeto comum, cuja força de gravitação provoca uma convergência paradoxal, produz uma estranha e amarga unidade, uma curiosa compressão centrípeta, tensionada a todo tempo pelo movimento oposto, isto é, pela tendência atomizante, fragmentária ou centrífuga. Por isso a sociabilidade, no Rio de Janeiro, hoje, parece costurada pelo avesso: macabra celebração comum da impossibilidade de comunhão. A cidade improvável sobrevive à sua própria exumação. Mas a que custos...

Examinando esse clima de violência, ou como prefere denominar, de "guerra civil molecular", Enzensberger percebe-a como esvaziada de fundamentos ideológicos, de convicções, ao contrário do que ocorrera, por exemplo, entre os guerrilheiros e terroristas dos anos 60 e 70, que sempre tinham necessidade de justificar seus atos. Para o autor, "nas guerras civis do presente, esvaiu-se a legitimidade. A violência libertou-se completamente de fundamentações ideológicas [levando os criminosos à] incapacidade de distinguir entre destruição e autodestruição" (Enzensberger, 1995, p. 16). Ainda em relação a isso, profere o seguinte:

Aos ameaçados restam apenas duas estratégias: fugir ou defender-se. Uma minoria privilegiada busca caminhos próprios de fuga: muda-se para um "paraíso de férias" qualquer, entrincheira-se em uma segunda residência ou um retiro, funda comunidades rurais ou seitas apartadas do meio social. A fuga dos milhões que não possuem meios materiais assume a forma da busca de asilo social e da migração de miseráveis. Quem não foge procura se proteger. Em nível mundial trabalha-se no fortalecimento de fronteiras contra os bárbaros. Mas no interior das metrópoles formam-se também arquipélagos de segurança rigorosamente guardados. Nas grandes cidades americanas, africanas e asiáticas já existem há tempos os bunkers dos felizardos, cercados por altos muros e arame farpado. Às vezes são bairros inteiros, nos quais se pode entrar apenas com permissões especiais. A paisagem é controlada por barreiras, câmeras eletrônicas e cães treinados. Guardas armados de metralhadoras complementam de suas torres a segurança da região. O paralelo com os campos de concentração é evidente, com apenas a diferença de que aqui é o mundo exterior que é visto como zona de potencial extermínio. Os privilegiados pagam pelo luxo com o total isolamento: eles se tornaram presas de sua própria segurança. (p. 40)

Sob esta lógica, seriam os pobres os mais afetados pela criminalidade 
MAIA, Rosemere. Reencontrando a cidade - um ensaio sobre a configuração das metrópoles na comtemporaneidade... Boletim Goiano de Geografia, 23 (1): 23 -40, jan./jun. 2003

urbana, já que sua possibilidade de se manterem afastados, exilados das ações violentas dos bandidos e policiais, é praticamente nula, ao contrário da situação daqueles que se refugiam em espaços exclusivos/privativos (como condomínios). Isso não significa afirmar que os moradores de locais de auto-segregação encontram-se totalmente imunes à violência urbana; até porque, como vimos afirmando, essas áreas não se descolam e apartam do contexto caótico da cidade. Apenas as chances de serem importunados por ações violentas são bem menores nesses espaços auto-segregados, dado todo o esquema de segurança, controle e proteção que, certamente, causaria em Foucalt (1979) um desejo incontrolável de rever a estrutura panóptica que analisou. Todo esse controle e segurança contrastam com a exposição aos riscos e à violência existentes nas ditas "áreas neutras", "locais onde se pode morrer" (Souza, 1995).

Outra característica fundamental das cidades contemporâneas tem sido a redução de seu uso massivo para teatralização política, o que, segundo Canclini (1997), foi determinado pela mistura de burocratização e "midiatização". Em relação ao primeiro aspecto, o autor refere-se à subordinação progressiva dos diferentes sujeitos sociais, antes convocados a manifestarem-se nas ruas, a cúpulas burocráticas. Quanto ao segundo, Canclini fala da substituição de formas argumentativas e críticas de participação pela "fruição de espetáculos nos meios eletrônicos em que a narração ou simples acumulação de anedotas prevalece sobre a reflexão em torno dos problemas, e a exibição fugaz dos acontecimentos sobre sua abordagem estrutural e prolongada" (p. 28). Aparecer em público é, hoje, ser coberto pela mídia. A cidade, em grande medida, perde seu caráter de lócus de manifestação do cidadão.

O papel da mídia na contemporaneidade é ímpar, assim como o é sua importância na leitura do mundo urbano. Park (1973) foi um visionário ao indicar o lugar de destaque dela nas grandes cidades, já que, para o autor, a mídia possibilitaria "representar os interesses da cidade como um todo, fazendo apelo a um sentimento que nem é local nem pessoal" (p. 59). Se fôssemos nos reportar ao momento atual, em que, dada a complexidade das metrópoles, tornamo-nos incapazes de apreendê-las em sua plenitude, poderíamos concordar com Park quando ele atribui à propaganda (ou, à mídia, aos meios massivos de comunicação, como diríamos) este papel de "colagem de fragmentos", capaz de nos permitir uma compreensão da totalidade, ainda que alegórica, das cida- 
MAIA, Rosemere. Reencontrando a cidade - um ensa1o sobre a configuração das metrópoles na comtemporaneidade... Boletim Goiano de Geografia, 23 (1): 23 -40, jan./jun. 2003

des. Levando-se em conta a época em que escreveu sobre esse papel da mídia e advertindo-se sobre seus vínculos com o ideário naturalizante da Escola de Ecologia Humana, suas considerações são, a nosso ver, extremamente atuais e procedentes, pois, como já observara o autor,

a publicidade passou a ser uma forma de controle social reconhecida, e a propaganda - "propaganda social" - se tornou uma profissão com uma técnica elaborada sustentada por um corpo de conhecimentos específicos. Um dos fenômenos característicos da vida citadina e da sociedade baseada em relações secundárias é que a propaganda viesse a ocupar um lugar tão importante em sua categoria. (Park, 1995, p. 59)

Lidando com imagens, com símbolos, a mídia torna possível "ver a cidade", o que, conforme sugere Egler (1992, p. 70), significa

perceber os seus fragmentos e decodificar os elementos constitutivos do espaço urbano". [Para a autora] pensada a cidade como um conjunto de símbolos dispersos, irá encontrar na documentação visual a linguagem mais completa para tratar da produção do conhecimento sobre os lugares e os territórios da cidade, em que a imagem é o processo de representação de símbolos dispersos.

A mídia, cria assim, vários olhares sobre a cidade. Logo, ela constrói várias cidades.

Se, por um lado, conforme nos sugere Canclini (1998), a mídia fragmenta - à medida que as informações que veicula sobre a cidade e sobre as "peripécias sociais são recebidas em casa, comentadas em família ou com amigos próximos, [de forma que] toda a sociabilidade e a reflexão sobre ela concentram-se em intercâmbios íntimos" -, por outro, ela contribui para superar a fragmentação, ao informar sobre questões que são de interesse comum dos citadinos (violência, conflitos sociais, poluição, transportes coletivos etc.). Quer dizer,

em uma escala mais ampla, é possível afirmar que o rádio e a televisão, ao relacionarem patrimônios históricos, étnicos e regionais diversos e difundi-los maciçamente, coordenam as múltiplas temporalidades de espectadores diferentes (Canclini, 1998, p. 289)

O desenvolvimento dos meios de comunicação, assim como o dos meios 
MAIA, Rosemere. Reencontrando a cidade - um ensaio sobre a configuração das metrópoles na comtemporaneidade... Boletim Goiano de Geografia, 23 (1): 23 -40, jan./jun. 2003

de transporte, foi um elemento decisivo para a superação das restrições territoriais, das restrições da localidade, produzindo efeitos inegáveis sobre nossa percepção espaço-temporal. A própria noção de distância (perto ou longe) demonstra ser, muito mais que detentora de um caráter puramente espacial, geográfico, um produto social: "sua extensão varia dependendo da velocidade com a qual pode ser vivenciada" (Bauman, 1999, p. 19).

No que se refere à nossa orientação no espaço, deparamo-nos com dificuldades para situar-nos não só na nossa própria cidade, como também em relação a outros lugares. Isso porque se constata a repetitividade e a banalização dos espaços, das construções: casas, seções de magazines e supermercados, shopping centers, campi universitários, todos parecem apontar para uma reprodução de modelos, uma serialização, sucedendo da mesma maneira "de cidade em cidade e de continente em continente, como se fossem reproduzidos por um mesmo módulo informatizado" (Chesneaux, 1996, p. 22),quando deveriam possuir marcas que expressassem algum grau de identidade própria e com a cidade.

A nossa orientação no tempo, igualmente abalada, deixa claro que a modernidade nos impingiu uma lógica temporal perversa, pautada na instantaneidade, na imediaticidade. Esse tempo imediato (ou incapacidade de localização no tempo) é traduzido no fast-food, no culto ao descartável, na utilização dos transportes aéreos (que evoluem, ao contrário do ônibus, do trem, num espaço vazio de sentido), no horário de verão, na "ausência do tempo" que caracteriza os shopping centers, na efemeridade presente na programação da TV, "um tempo comprimido no imediato, um tempo rigidamente programado e tarifado, um tempo quantitativo" (Chesneaux, 1996, p. 24).

Desorientados espaço-temporalmente, os moradores das cidades acabam perdendo, em certa medida, a consciência urbana, pois, como sugere Carlos (1994), "habitar hoje a metrópole tem um sentido diverso, mudando hábitos e comportamentos, bem como formas de apropriação do espaço público, [além de dissolver] antigos modos de vida e relações entre as pessoas", seja de vizinhança, seja familiares, seja, sobretudo, políticas (em seu sentido mais amplo). Constata-se, assim, uma tendência à emergência de relações de estranhamento, à eclosão de conflitos, à "justaposição de atividades parcelares cujo conjunto escapa ao indivíduo. Em decorrência, a produção de um cotidiano onde a vida aparece atomizada, ao mesmo tempo que superorganizada" (p. 193-194). 

comtemporaneidade... Boletim Goiano de Geografia, 23 (1): 23 -40, jan./jun. 2003

Viver nas cidades, contudo, não deve ser considerado, exclusivamente, como sinônimo de dissolver-se na massa e no anonimato. Ao contrário, pode implicar uma procura, por meio da intimidade doméstica e de encontros confiáveis, de formas seletivas de sociabilidade (Canclini, 1997, p. 287). E isso não é prerrogativa ou privilégio somente daqueles que podem se auto-segregar, fechar-se em locais privativos (como condomínios, clubes, shopping centers), mas tem sido a tônica, também, de grupos populares que, cada vez em menor intensidade, deixam seu pedaço e se arriscam pelos pórticos da cidade.

Nas grandes cidades, o sentido de casa - sua concepção e funcionalidade - foi alterado. Ela não é, como sugerira Da Matta (1997, p. 57), tão-somente um "espaço de calma, repouso, recuperação e hospitalidade; enfim, de tudo aquilo que define nossa idéia de 'amor', 'carinho' e 'calor humano'. Muitas vezes, tal qual a rua, ela assume um cariz pragmático; ou seja, passa a ser um lugar de passagem, de dormir, onde - em função da dinâmica imposta pelo mundo urbano a todos os seus moradores, assim como em razão das transformações ocorridas na própria estrutura familiar, no estilo de vida - pouco tempo se tem para partilhar, comungar experiências. De casulo, lugar de aconchego, a casa passa a ser local de informação.

A cultura do consumo é um outro elemento a caracterizar as sociedades contemporâneas, em especial a vida urbana. Isso não significa dizer que, em estágios anteriores, o consumo não existisse. É claro que, na qualidade de seres humanos, somos fadados ao consumo, nas suas mais diferentes nuanças, desde tempos imemoriais. Contudo, há na atualidade elementos distintivos que induzem o consumo a assumir um caráter "profundo" e "fundamental" na vida dos homens, diferentemente do que ocorria no estágio inicial da modernidade, quando os indivíduos eram enquadrados como produtores, a exemplo do que nos sugere Bauman (1999, p. 88):

Aquela velha sociedade moderna engajava seus membros primordialmente como produtores e soldados; a maneira como moldava seus membros, a "norma" que colocava diante de seus olhos e os instava a observar, era ditada pelo dever de desempenhar estes dois papéis. A norma que aquela sociedade colocava para seus membros era a capacidade e a vontade de desempenhá-los. Mas no seu atual estágio final moderno (Giddens), segundo estágio moderno (Beck), supramoderno (Balandier) ou pós-moderno, a sociedade moderna tem pouca necessidade 
MAIA, Rosemere. Reencontrando a cidade - um ensaio sobre a configuração das metrópoles na comtemporaneidade... Boletim Goiano de Geografia, 23 (1): 23 -40, jan./jun. 2003

de mão-de-obra industrial em massa e de exércitos recrutados; em vez disso, precisa engajar seus membros pela condição de consumidores.

A mudança de ênfase (de produtores a consumidores) na sociedade contemporânea faz que se verifiquem transformações não só na esfera da economia, mas, sobremaneira, nos aspectos sociais, políticos, culturais e ideológicos, sem falar em questões relacionadas à subjetividade. A grande "questão filosófica" que se coloca hoje é se o homem consome para viver ou se vive para consumir (Bauman, 1999, p. 89).

O homem submetido à cultura do consumo é um eterno insatisfeito, posto que seus desejos jamais podem ser contemplados em sua plenitude, à medida que sempre surge um produto novo, algo que lhe estará faltando. Destarte, segundo Castro (1998, p. 58),

os sujeitos humanos são, então, susceptíveis às experiências que enfatizam a falta, ou que, em outras palavras, incitam a novas "necessidades" de consumo, já que as possibilidades de se criar novos significados culturais, e, portanto, novos bens simbólicos são ilimitadas [...] a realidade social é construída de acordo com as orientações desta cultura do consumo. Isto significa que, em primeiro lugar, a abordagem geral em relação ao mundo material, e também social, está marcada por uma busca de novidades resultando em atitudes e comportamentos sequiosos de se mostrarem atuais e "na moda", pois isto lhes garante uma inserção e um reconhecimento social. Conseqüentemente, a idéia de "novo" é limítrofe à idéia de "melhor". Quem busca atualizar-se, busca, de igual modo, impor-se aos olhos dos outros. Desta maneira, a cultura do consumo promove, ideologicamente, a cultura da obsolescência, a cultura da renovação pela renovação. Nesta perspectiva, a experiência ganha densidade na medida em que se legitima sobre a qualidade efêmera dos efeitos que provoca, onde a presença fugidia e evanescente das coisas e das vivências adquire um valor paradigmático para validar o sentido mesmo da realidade.

Numa sociedade de consumo, portanto, nenhum desejo é encarado como o último, nem tampouco se estabelece, entre o consumidor e aquele objeto que tanto quis e, enfim, conseguiu, um pacto aos moldes do "até que a morte nos separe". Bauman (1999, p. 89-90) observa que, em função da fugacidade, da efemeridade, todos os compromissos deveriam possuir uma cláusula adicional: 
MAIA, Rosemere. Reencontrando a cidade - um ensaio sobre a configuração das metrópoles na comtemporaneidade... Boletim Goiano de Geografia, 23 (1): 23 -40, jan./jun. 2003

"até segunda ordem". Isso porque, numa sociedade de consumo, a temporalidade do objeto refere-se à sua conveniência. E essa conveniência parece cada vez mais breve. A satisfação do consumidor deve ser instantânea, o que significa que o manejo do objeto desejado deve prescindir de grandes habilidades e que, tão logo alcançada, essa satisfação deixará de existir, pois há uma perda imediata do interesse pelo objeto, no momento em que é obtido.

A moda e o estilo, por sua vez, têm sido utilizados como mecanismos que, sobretudo nas grandes cidades, acabam enquadrando os indivíduos socialmente. Park (1973, p. 62) já observara tal tendência nas grandes cidades, onde o

status do indivíduo é determinado num grau considerável por sinais convencionais - por moda e aparência - e a arte da vida reduz-se em grande parte a esquiar sobre superfícies finas e a um escrupuloso estudo de estilos e maneiras.

Esse mesmo autor fala da possibilidade, colocada pela cidade, de vivência, por um mesmo indivíduo, de vários mundos e, por isso mesmo, de vários papéis. Se, por um lado, isso pode ser fascinante, por outro, afiança o autor, pode ser uma experiência perigosa, pois se há uma contigüidade entre estes diferentes mundos, em grande medida, eles podem ser altamente diferenciados. Segundo ele,

isto tende a dar à vida citadina um caráter superficial e adventício; tende a complicar as relações sociais e produzir tipos individuais novos e divergentes. Introduz, ao mesmo tempo, um elemento de acaso e aventura que se acrescenta ao estímulo da vida citadina e lhe confere uma atração especial para nervos jovens e frescos. $\mathrm{O}$ atrativo das cidades grandes é talvez uma conseqüência de estímulos que agem diretamente sobre os reflexos. Enquanto tipo de comportamento humano, pode ser explicado, numa espécie de tropismo, como a atração de uma mariposa pela chama. (Park, 1973, p. 62)

A cidade, por sua diversidade, permite a identificação pelo indivíduo de algum local onde ele se sinta capaz de expandir-se e permanecer à vontade. E se essa identificação, em princípio, não existe, pode ser criada, posto que a cidade grande permite a excentricidade, a esquisitice, seja de sujeitos individuais ou de grupos.

Park (1973) coloca, assim, para a análise da cultura urbana, elementos 
MAIA, Rosemere. Reencontrando a cidade - um ensaio sobre a configuração das metrópoles na comtemporaneidade... Boletim Goiano de Geografia, 23 (1): 23 -40, jan./jun. 2003

que nos remetem à consideração de códigos, símbolos e valores necessários à compreensão do lugar ocupado pelos sujeitos nesse contexto e, mais que isso, remetem-nos à definição dos espaços (e, quem sabe, até dos territórios) por onde transitam, desenvolvem sua sociabilidade, forjam sua identidade.

Featherstone (1995), por sua vez, acredita que as pessoas que vivem nas cidades acabam por se envolver num jogo de signos e códigos, de faz-de-conta, que, dada sua ausência de profundidade, sua artificialidade e opacidade,

não podem ser decodificados de forma a dar acesso a qualquer significado revelador ou a uma noção de verdade fundamental. A vida cotidiana torna-se uma "mélange fantástica de ficção e valores estranhos" que apreende o sentido surreal como uma presença cotidiana, como excesso, estilo e experimentação e também como acaso, banalidade e repetição de imagens de rua. (p. 141)

O citadino vive em constante processo de experimentação, sua vida é um simulacro. Seja nos parques temáticos, nos shopping centers ou, até mesmo, nos museus, os indivíduos inebriam-se com o lúdico, abandonam hierarquias simbólicas, submetem-se a um processo de "instantaneamento", o que demonstra que nesses espaços, onde se tornam evidentes a desordem cultural e o ecletismo estilístico, o consumo e o lazer devem ser vividos, sempre, como experiências.

\section{Considerações finais}

Várias outras questões, com toda certeza, poderiam aqui ter sido pontuadas e analisadas. Não foi nossa intenção, entretanto, esgotar o assunto.

Consideramos que a cidade apresenta-se ainda como uma grande incógnita aos seus sujeitos e, por isso mesmo, carece de análises incisivas, partilhadas, por parte dos mais variados campos do saber. Isso significaria avançar na busca da transdisciplinaridade, perspectiva capaz, a nosso ver, de superar quaisquer ranços interdisciplinares que se pautem na defesa de uma especificidade que segmenta, parcializa a análise, dificultando a apreensão do fenômeno em suas múltiplas determinações e matizes.

Àqueles que se voltam para a análise do urbano, faz-se necessária a adoção de uma perspectiva capaz de ver o invisível e ouvir o não- dito, sem a pretensão de 
MAIA, Rosemere. Reencontrando a cidade - um ensaio sobre a configuração das metrópoles na comtemporaneidade... Boletim Goiano de Geografia, 23 (1): 23 -40, jan./jun. 2003

aprisioná-los num academicismo arrogante que, na busca de conhecer, desvendar, de tudo faz para esconder um sentimento que aterroriza indistintamente todos os sujeitos sociais: o medo. Nesse sentido, citamos, para finalizar, Chnaiderman \& Hallack (1995, p. 39), que tratam, justamente, desse sentimento:

A rua povoou-se de estranhos personagens. Ganhamos outros olhos. No momento iniciático, um homem com um bastão à minha frente. Criou-se um novo canal de televisão no planeta Terra. Medo. Entrar na padaria sem ser para tomar café, ir até a banca de jornal sem ser para comprar nada, falar com o fruteiro da esquina sem precisar de fruta. Na calçada, estranha coreografia. Pessoas atravessam a rua, desviando-se. O que antes parecia imóvel, baila. A cidade não é mais só cimento. Existem casas invisíveis, castelos com torres lindas, a paisagem é absolutamente outra. O medo só pode ser vencido na intensidade do encontro. Os medos gestamse na intensidade do encontro.

Àqueles que se voltam para a análise do urbano, é vital "deixar-se perder na cidade". Disso depende o encontro com ela e com seus personagens.

\section{ABSTRACT \\ Study about the city: an essay about the configuration of the metropolis in the contemporanity - it's dilemmas and perspectives}

The city, especially the metropolis, will be here discussed. Its actors, its (des)organization interns, its conflicts and its fragments will have been evidenced, although we are aware of the complexity that the urban world presents neither will allow us comprehend it in all its wealth and magnitude, nor study the totality of its (con)traditions, symbolisms, ideologies and social and geographical practices. Therefore, we are willing to develop a brief discussion about the way how the cities - in a exceptional manner, the "big city" - have reacted and, at the same time, influenced in the changes that have been undergone in the society (in its range: economical, political, cultural, ideological aspects) in the beginning millennium. Thus, we are going to which draw us to reveal these changes and, simultaneously, placing us the challenge of trying predict some elements that indicate us the "destiny of the cities."

Key words: City/ Sociability/ Segregation/ Consumption. 
MAIA, Rosemere. Reencontrando a cidade - um ensaio sobre a configuração das metrópoles na comtemporaneidade... Boletim Goiano de Geografia, 23 (1): 23 -40, jan./jun. 2003

\section{REFERÊNCIAS}

ARISTÓTELES. A política. Rio de Janeiro: Ática, [s.d.].

BAUMAN, Zygmunt. Globalização: as conseqüências humanas. Rio de Janeiro: Zahar, 1999.

CANCLINI, Néstor Garcia. Consumidores e cidadãos: conflitos multiculturais da globalização. Rio de Janeiro: Ed. UFRJ, 1997.

. Culturas híbridas. São Paulo: EDUSP,1998.

CARLOS, Ana Fani Alessandri. A natureza do espaço fragmentado. In: SANTOS, M.; SOUZA, M. A. A.; SILVEIRA, M. L. (Org.). Território, globalização e fragmentação. São Paulo: Hucitec, 1994. p. 191-197.

CASTELLS, Manuel. A sociedade em rede. In: . A era da informação: economia, sociedade e cultura. São Paulo: Paz e Terra, 1999. v. 1.

CASTRO, Lúcia Rabello de. Consumo e a infância barbarizada: elementos da modernização brasileira. In: . Infância e adolescência na cultura do consumo. Rio de Janeiro: Nau, 1998.

CHNAIDERMAN, Miriam; HALLACK, Regina. Estranhas urbanidades. In: MAGALHÃES, Maria Cristina (Org.). Na sombra da cidade. São Paulo: Escuta, 1995.

CHESNEAUX, Jean. Modernidade mundo. Petrópolis: Vozes, 1996.

DA MATTA, Roberto. A casa \& a rua: espaço, cidadania, mulher e morte no Brasil. Rio de Janeiro: Rocco, 1997.

EGLER, Tamara Tania Cohen. A imagem do Rio de Janeiro na televisão. $C a-$ dernos do IPPUR/UFRJ, ano 6, n. 1, dez. 1992.

ENZENSBERGER, Hans Magnus. Guerra civil. São Paulo: Companhia das Letras, 1995.

FEATHERSTONE, Mike. Cultura do consumo e pós-modernismo. São Paulo: Studio Nobel, 1995.

FORTUNA, Carlos. Introdução: sociologia, cultura e globalização. In: Cidade, cultura e globalização: ensaios de sociologia. Oeiras: Celta, 1997. FOUCAULT, Michel. Microfisica do poder. Rio de Janeiro: Graal, 1979. 
MAIA, Rosemere. Reencontrando a cidade: um ensaio sobre a configuração das metrópoles ... Boletim Goiano de Geografia, 23 (1): 23 - 40, jan./jun. 2003

GIDDENS, Anthony. As conseqüencias da modernidade. São Paulo: Ed. UNESP, 1991.

LYNCH, Kevin. Una teoría de la buena forma urbana. In: _. La buena forma de la ciudad. Barcelona: Editorial Gustavo Gili.

MAGNANI, José Guilherme Cantor. Rua, símbolo e suporte da experiência urbana. Disponível em: <www.aguaforte.com/antropologia>. Acesso em 2002. MUMFORD, Lewis. A cidade na História: suas origens, transformações e perspectivas. São Paulo: Martins Fontes, 1991.

PARK, Robert E. A cidade: sugestões para a investigação do comportamento humano no meio urbano. In: VELHO, Otávio (Org.). O fenômeno urbano. Rio de Janeiro: Zahar, 1973. p. 26-67.

SENNETT, Richard. O declínio do homem público. São Paulo: Companhia das Letras, 1998.

SIMMEL, Georg. A metrópole e a vida do espírito. In: FORTUNA, Carlos (Org.). Cidade, cultura e globalização: ensaios de sociologia. Oeiras: Celta, 1997.

SOARES, Luiz Eduardo. O herói serial e a sensibilidade pragmática: alguns comentários sobre a violência e a nova sociedade civil, no Rio de Janeiro. In: Soares et al. (Org.). Violência e política no Rio de Janeiro. Rio de Janeiro: Relume Dumará; ISER, 1996.

SOJA, Edward. O desenvolvimento metropolitano pós-moderno nos EUA: virando Los Angeles pelo avesso. In: SANTOS et al. (Org.). Território: globalização e fragmentação. São Paulo: ANPUR; Hucitec, 1994.

SOUZA, Marcelo Lopes de. O território: sobre espaço e poder, autonomia e desenvolvimento. In: CASTRO, Iná et al. (Org.). Geografia, conceitos e temas. Rio de Janeiro: Bertrand Brasil, 1995. p. 77-116.

Recebido em: 1/6/2003 Aprovado em: 10/10/2003 